\title{
RGB-02 (biosimilar pegfilgrastim) in the treatment of chemotherapy-induced neutropenia
}

\author{
Dóra Sántha1, András Illés², Ildikó Aradi², Károly Horvát-Karajz² \& Zsuzsanna Kahán*,1 \\ ${ }^{1}$ Department of Oncotherapy, University of Szeged, Korányi fasor 12, H-6720, Szeged, Hungary \\ ${ }^{2}$ Gedeon Richter Plc., Gyömröi út 19-21, H-1103, Budapest, Hungary \\ *Author for correspondence: Tel.: +36 6254 5404; Fax: +36 6254 5922; kahan.zsuzsanna@med.u-szeged.hu
}

Pegfilgrastim is widely used for the prevention of chemotherapy-induced neutropenia. The development and use of biosimilar agents help to rationalize healthcare expenditure and improve access to modern therapies to all who need them. This review focuses on pegfilgrastims with important role in oncology supportive care. RGB-02 (Gedeon Richter) is a proposed biosimilar to pegylated granulocyte-colony stimulating factor (Neulasta ${ }^{\circledR}$, Amgen) with sustained release properties. The clinical analyses in three randomized clinical studies provided comparative data between RGB-02 and Neulasta, in a Phase III study patients receiving docetaxel-doxorubicin chemotherapy treatment equivalence was found. No difference was detected in any safety measure including immunogenicity; treatment switch, from the reference product to RGB-02 proved safe. Long-acting pegylated filgrastim RGB-02 has successfully accomplished various steps of biosimilar development.

First draft submitted: 30 November 2018; Accepted for publication: 11 March 2019; Published online: TBC

Keywords • biosimilar $\bullet$ cancer $\bullet$ neutropenia $\bullet$ pegfilgrastim $\bullet$ pharmacoeconomics $\bullet$ supportive therapy

Cancer is a major global public health problem, 42 million new diagnoses and 9 million cancer deaths are registered yearly [1-3]. In Europe, 2635 million cases and 1291 million deaths were counted in 2012 [4]. In the USA, 1,735,350 new cancer cases and 609,640 cancer deaths were predicted for the year 2018 [2]. In Hungary, the total number of new cases and related deaths in the period 2006-2015 were 712,000 and 331,000, respectively [5]. Incidence is still rising worldwide while thanks to preventive measures and modern therapies, cancer fatality is decreasing in well-developed countries $[2,4,5]$. Since survival in advanced cancer is extended by modern treatments in general, the prevalence of the disease and the number of patients to be treated are increasing. Taking into account the impact that cancer makes on life (morbidity and premature death) and its upward trend, it is foreseen that cancer will soon step to the first place from the second by becoming the disease group that causes the greatest burden [4].

In recent years, great progress has been made in cancer care including medical therapy. New treatment options such as molecular-targeted therapies and immune therapies frequently based on costly diagnostic methods called personalized or precision medicine provide improved outcome benefit. Although these sophisticated methods are increasingly applied in oncology practice, chemotherapy still remains the backbone of systemic treatments. Myelosuppressive chemotherapy regimens impair normal hematopoiesis in the bone marrow including the production of neutrophil granulocytes. Neutropenia increases the risk of infection and may bias therapeutic effectiveness by causing treatment interruption or delay. The prevention or treatment of neutropenia with granulocyte-colony stimulating factor (G-CSF, filgrastim) is a standard supportive care measure [6-11]. Filgrastim accelerates the proliferation, maturation and release of neutrophil granulocytes [12]. Filgrastim was first approved in 1991 by the US FDA [13]. Pegfilgrastim is a pegylated form of filgrastim. The modification of the molecule results in prolonged bioavailability due to decreased clearance by the kidney when elimination is left almost exclusively to neutrophil granulocytes [14]. The advantage of long-acting filgrastims such as pegfilgrastim over nonpegylated filgrastims is that, due to their increased molecular size, they are not eliminated from the body via renal clearance and therefore their half-life is substantially increased, which allows one single administration per chemotherapy cycle ensuring 
almost complete patient compliance. Pegfilgrastim (Neulasta ${ }^{\circledR}$, Amgen) [15] was first approved in 2002 in the USA and then in Europe [16]. Another pegylated long-acting filgrastim, the lipefilgrastim (Lonquex ${ }^{\circledR}$, Teva) [17] has received regulatory approval and entered the market place in 2013 [18,19]. Pharmacoeconomic analyses showed that the long-acting filgrastim analog Neulasta was more cost effective and safe than supportive therapy based on filgrastim [20,21]. All forms bind to the human G-CSF receptor stimulating proliferation, differentiation and activation of neutrophils. Treatment given subcutaneously starts at least $24 \mathrm{~h}$ after the completion of cytotoxic chemotherapy [22].

As a result of pegylation, pegfilgrastim is administered once-per-cycle, while filgrastim is given once daily, usually for 7-10 days. It is agreed that filgrastim and pegylated filgrastim have similar efficacy and safety profiles [23-27]. In a literature review, a single dose of pegylated filgrastim was found at least as effective as daily administered filgrastim [28]. Pegylated filgrastim seemed feasible and safe as primary and secondary prophylaxis in the elderly population also $[29,30]$. The use of pegylated filgrastim represents a reliable and convenient option for both patients and their care givers.

\section{Overview of the market}

Health expenditure on cancer increased by $>100 \%$ in the past 20 years [4]; however, country-specific expenses vary to a great extent $[4,31]$. Eastern and central European countries spend about $16-45 \%$ of the European average cancer-related healthcare costs $[4,29]$. Clearly, in these lower-income countries limited resources are spent to high- or low-cost medicines either [32,33]. The amount spent on anticancer medicines is predicted to exceed the 140 billion EUR mark by 2020 globally [34-36]. There is a dilemma how to ensure or improve access to therapy to all patients and provide them modern care. Biologics are produced in genetically engineered living systems. Costs related to biologics represent about $20 \%$ of all costs in oncology [34-36]. The development and use of biosimilar agents (a similar version of the originator biologic) provide possibility to rationalize expenses in all healthcare systems. While biologics are predicted to generate USD 290 billion in revenue and comprise $27 \%$ of the pharmaceutical market by 2020 worldwide, it is foreseen that an expanding proportion of the market will belong to biosimilars [37].

The regulatory process of biosimilar approval in Europe was established earlier than in the USA. Since 2001 when biosimilar legislation emerged $>50$ biosimilars corresponding to 25 distinct agents have been authorized by the EMA, most of them being approved in recent years [38]. Further rapid increase in number is foreseen for the year 2020 when widely utilized originator biologics will lose their patent exclusivity. True biosimilars are approved in highly regulated regions after passing a rigorous evaluation procedure. Nevertheless, due to the strong need, many others the so called 'copy biologics' are offered in the less regulated markets; for these compounds, no strict comparability, biosimilarity is demonstrated. This is why at present there are altogether 450 commercialized, which are 'following biologics' worldwide and 250 are in the pipelines [37].

Nevertheless, there are country-specific barriers and concerns among users that delay spread of biosimilars [32,39]. Biosimilar drugs are biological medicines that are highly similar but not identical to already licensed agents, the so called reference or originator products [35]. High-quality biosimilars are authorized by reputable regulatory agencies such as the FDA or the EMA provided that comprehensive evaluation indicates similarity between the original biologic and its biosimilar by means of purity, safety and efficacy [40-42]. Biosimilarity approval is granted on comparative analytical, preclinical investigations, and clinical data are also required. When the patent on reference medication expires, biosimilar drugs, if qualify for registration, may come out on the market. The clinical and economic benefit of the development of biosimilars is twofold: savings for the healthcare budget, and access to biologics without restriction to all who need them $[32,39]$. The first filgrastim biosimilar was approved in Europe in 2008 [41]. At present over 50 biosimilars are approved by EMA [44] among which 7 filgrastim biosimilars are included (Table 1). Recently biosimilar pegfilgrastims also received EMA (Table 2) [44] and FDA authorization [45] while some other compounds are in different stages of development.

Two main clinical development approaches can be clearly distinguished in the case of approved biosimilar pegfilgrastim developments. In the case of the reduced clinical approach (Udenyca ${ }^{\circledR}$, Pelmeg ${ }^{\circledR}$ ), only healthy volunteer studies are conducted and the comparability of the therapeutic effect to Neulasta is concluded on the basis of the comparable pharmacodynamic response in healthy volunteers. The rationale behind this approach is that the mechanism of action of pegfilgrastim (i.e., stimulation of neutrophil granulocyte proliferation) is basically the same in healthy volunteers and patients treated with cytotoxic chemotherapy, hence neutrophil granulocyte count-related end points in healthy volunteers can be considered as surrogate end points for the conclusion of 


\begin{tabular}{|c|c|c|c|}
\hline Name & Active substance & Therapeutic area & Date of authorization \\
\hline Accofil $^{\circledR}$ (Accord Healthcare Ltd.) & Filgrastim & Neutropenia & 18 September 2014 \\
\hline Filgrastim Hexal ${ }^{\circledR}$ (Hexal) & Filgrastim & $\begin{array}{l}\text { Cancer, } \\
\text { hematopoietic stem cell } \\
\text { transplantation, } \\
\text { neutropenia }\end{array}$ & 6 February 2009 \\
\hline Grastofil $^{\circledR}$ (Apotex Europe BV) & Filgrastim & Neutropenia & 18 October 2013 \\
\hline Nivestim ${ }^{\circledR}$ (Hospira) & Filgrastim & $\begin{array}{l}\text { Cancer, } \\
\text { hematopoietic stem cell } \\
\text { transplantation, } \\
\text { neutropenia }\end{array}$ & 8 June 2010 \\
\hline Ratiograstim ${ }^{\circledR}$ (Ratiopharm) & Filgrastim & $\begin{array}{l}\text { Cancer, } \\
\text { hematopoietic stem cell } \\
\text { transplantation, } \\
\text { neutropenia }\end{array}$ & 15 September 2008 \\
\hline Tevagrastim $^{\circledR}$ (Teva) & Filgrastim & $\begin{array}{l}\text { Cancer, } \\
\text { hematopoietic stem cell } \\
\text { transplantation, } \\
\text { neutropenia }\end{array}$ & 15 September 2008 \\
\hline Zarzio $^{\circledR}$ (Sandoz) & Filgrastim & $\begin{array}{l}\text { Cancer, } \\
\text { hematopoietic stem cell } \\
\text { transplantation, } \\
\text { neutropenia }\end{array}$ & 6 February 2009 \\
\hline
\end{tabular}

\section{Table 2. Pegfilgrastim biosimilars with EMA approval or positive CHMP opinion.}

\begin{tabular}{|c|c|c|}
\hline Name & Active substance & Date of authorization \\
\hline Udenyca $^{\circledR}$ (ERA Consulting GmbH) & Pegfilgastrim & 20 September 2018 \\
\hline Pelgraz $^{\circledR}$ (Accord Healthcare Ltd.) & Pegfilgastrim & 20 September 2018 \\
\hline Fulphila ${ }^{\circledR}$ (Mylan) & Pegfilgastrim & 20 September 2018 \\
\hline Pelmeg ${ }^{\circledR}$ (Cinfa Biotech S.L) & Pegfilgastrim & 20 September 2018 \\
\hline Ziextenzo $^{\circledR}$ (Sandoz GmbH) & Pegfilgastrim & 20 September 2018 \\
\hline
\end{tabular}

clinical efficacy. In the case of the another approach (Ziextenzo ${ }^{\circledR}$, Fulphila ${ }^{\circledR}$, Pelgraz ${ }^{\circledR}$ ) extensive clinical program is conducted with Phase III comparative studies. Therefore, in addition to the comparative pharmacodynamic data collected in healthy volunteers, with this approach, the equivalent therapeutic effect to Neulasta is directly demonstrated as well in patient studies similar to the pivotal studies of Neulasta with the same therapeutic efficacy end points. Moreover, in the case of these developments, the sustained therapeutic effect of the biosimilar pegfilgrastim is also demonstrated since the patients receive pegfilgratim administrations in each chemotherapy cycle and the efficacy is evaluated not only in the first cycle but also in the subsequent cycles. The advantage of this approach is also that it provides extensive patient safety data on the biosimilar product itself in patients, while in the case of the reduced clinical approach comparable safety in patients is concluded on the basis of biosimilarity demonstrated at quality and pharmacokinetic (PK)/pharmacodynamic (PD) level.

The approval and introduction of biosimilars to market reduce costs [34,35]. Biosimilar use-generated savings in healthcare budget may enhance access to new and expensive biologicals and ultimately, improve patients' health and quality of life. Since the use of biosimilars is a common interest of different stakeholders including clinicians, payers, patients and manufacturers, the landscape of medicines in oncology is going to change despite country-specific barriers and hurdles [32,39].

\section{RGB-02, a proposed biosimilar pegfilgrastim's development} Introduction to the compound

Filgrastim, approved in 1991 by FDA is a nonglycosylated protein with a methionine group attached to the human amino acid sequence and is produced by recombinant-DNA technology in Escherichia coli. Filgrastim undergoes rapid renal clearance and requires daily administration during chemotherapy. In contrast, pegfilgrastim, a covalent conjugate of filgrastim with a single $20 \mathrm{kDa}$ polyethylene-glycol is mainly eliminated by neutrophil-mediated clearance, resulting in a long serum half-life and therefore allows single administration per chemotherapy cycle. 
This clear advantage over filgrastim, which has to be administered daily, leads to a better patient compliance and results in improved clinical outcomes. Development of biosimilars is regulated through specific guidelines to guarantee similarity with the reference product in quality, PKs, PDs and clinical efficacy as well as the safety profile.

The clinical development program for RGB-02 as a biosimilar drug was set up considering all relevant CHMP guidelines and Scientific Advices received from the EMA CHMP and European National Authorities, and comprises to date three randomized, double-blind clinical studies [40-42]:

- A single-center PK/PD study comparing RGB-02 with Neulasta in healthy volunteers (study code 74080).

- A single-center PK/PD study comparing RGB-02 with Neulasta in healthy volunteers (study code: RGB-02001).

- A multicentric efficacy and safety study comparing RGB-02 with Neulasta in breast cancer patients (study code: RGB-02-101, EudraCT number 2013-003166-14).

The originator drug Neulasta [15] sourced from the EU was selected as reference product for all three studies, which were performed in Europe either as single center in the UK or involving multiple centers in Hungary, Bulgaria, Croatia, Czech Republic, Romania, Russia, Serbia and Ukraine. The performance and supervision of these clinical studies followed the principles of Good Clinical Practice as laid down in ICH E 6 [46].

\section{Comparable effects of RGB-02 \& Neulasta \\ Pharmacodynamics}

The main purpose of the clinical studies 74080 and RGB-02-001 was to establish the comparative PK profile of RGB-02 and to investigate PD properties compared with the reference product Neulasta.

For absolute neutrophil count (ANC)-related PD margins, an acceptance range of $85-117.65 \%$ was selected for study 74080 to allow the detection of slight differences. The CI for the primary PD end point (ANC AOBEC 0 -tlast) was equivalent to a 95\% CI and for the secondary PD end points to a $95.96 \% \mathrm{CI}$.

For the subsequent Study RGB-02-001 the comparability acceptance 95\% CI range of 80-125\% was selected for the PD analysis following the scientific advice obtained from EMA after analyzing the results from study 74080 .

Pegfilgrastim, like filgrastim, induces neutrophil proliferation leading to a marked increase in peripheral blood neutrophil count within $24 \mathrm{~h}$; this effect can be observed in healthy subjects as well as cancer patients receiving chemotherapy [27]. The relationship between ANC as a PD parameter and the expected clinical efficacy has led to ANC being an accepted and established surrogate end point for assessing the effect of G-CSF [47].

Therefore ANC-related PD end points were included in the PK/PD studies for demonstrating biosimilarity between RGB-02 and Neulasta. The expected results were considered to have a high predictive value for the subsequent comparative efficacy and safety study (RGB-02-101), which would provide additional supportive evidence to establish a therapeutically equivalent efficacy of RGB-02 and Neulasta.

Unlike in case of filgrastim, stem cell mobilization is not an approved indication for Neulasta. Nevertheless, it was decided to measure and compare the progenitor mobilizing effect of RGB-02 with Neulasta in the first comparative PK/PD study 74080 by assessing blood CD $34^{+}$counts. Formal statistical analysis was not planned for this secondary end point due to the high variability of $\mathrm{CD} 34^{+}$cell count-related parameters. Consequently, in study 74080 the primary PD end point was the area over the baseline effect curve (AOBEC) for absolute neutrophil count $\left(\mathrm{ANC}_{0 \text {-tlast }}\right)$ and the secondary PD end points were $\mathrm{ANC}_{\max }, \mathrm{ANC} \mathrm{T}_{\max }, \mathrm{ANC} \mathrm{AUC}_{0 \text {-tlast }}, \mathrm{CD} 34^{+} \mathrm{AOBEC}_{0-\text { tlast }}$, $\mathrm{CD} 34^{+} \mathrm{AUC}_{0 \text {-tlast }}, \mathrm{CD} 34^{+}{ }_{\text {max }}$ and $\mathrm{CD} 34^{+} \mathrm{T}_{\text {max }}$; results from this study demonstrated high level of similarity between RGB-02 and Neulasta based on all PD parameters. Table 3 represents the results for ANC-related end points of study 74080 .

When interpreting results of the first PK/PD study it is important to stress that high level of similarity of PD end points between RGB-02 and Neulasta has more clinical relevance than the PK parameters. The blood CD34 ${ }^{+}$ count results, although not tested for statistical significance also support the similarity of the two products.

The PD results from study 74080 confirming comparability between the two compounds were used to plan for a second PK/PD Study RGB-02-001 where PD analysis was selected as primary objective. As primary PD end points $A N C A O B E C_{0 \text {-tlast }}$ and $\mathrm{ANC}_{\max }$ were selected; parameters for secondary $\mathrm{PD}$ end points were $\mathrm{ANC} \mathrm{T}_{\max }$ and $\mathrm{ANC} \mathrm{AUC}_{0 \text {-tlast }}$.

Table 4 presents the results of the second comparative PK/PD study (Study RGB-02-001). 


\begin{tabular}{|c|c|c|c|c|c|c|}
\hline \multirow[t]{2}{*}{ Parameter } & \multicolumn{2}{|c|}{ RGB-02 } & \multicolumn{2}{|c|}{ Neulasta ${ }^{\circledR}$} & \multirow[t]{2}{*}{ Ratio $^{\ddagger}$} & \multirow[t]{2}{*}{$\alpha$-adjusted $\mathrm{Cl}^{\S}$} \\
\hline & $\mathbf{N}$ & Adjusted mean ${ }^{\dagger}$ & $\mathrm{N}$ & Adjusted mean ${ }^{\dagger}$ & & \\
\hline $\begin{array}{l}\text { ANC AOBEC }_{0 \text {-tlast }} \\
\left(\times 10^{9} \cdot \mathrm{h} / \mathrm{l}\right)\end{array}$ & 96 & 3490 & 96 & 3290 & 106.12 & $(99.28,113.43)$ \\
\hline $\begin{array}{l}\text { ANC AUC } \text { A-tlast } \\
\left(\times 10^{9} \cdot \mathrm{h} / \mathrm{l}\right)\end{array}$ & 96 & 5040 & 96 & 4920 & 102.31 & $(99.83,104.85)$ \\
\hline $\mathrm{ANC}_{\max }\left(\times 10^{9} / \mathrm{I}\right)$ & 96 & 30.463 & 96 & 29.242 & 104.18 & $(100.60,107.88)$ \\
\hline \multicolumn{7}{|c|}{$\begin{array}{l}\text { Results obtained from parametric analysis of } \log _{\mathrm{e}} \text {-transformed pharmacodynamic parameters } \\
\text { a random effect and baseline concentrations fitted as a covariate. } \\
\dagger \text { Adjusted geometric mean from ANCOVA. } \\
\ddagger \text { Ratio of adjusted geometric means defined as RGB-02/Neulasta. } \\
\S \mathrm{CI} \text { for ratio of adjusted geometric means. } \\
\text { ANC: Absolute neutrophil count; ANCOVA: XXX; AOBEC: Area over the baseline effect curve. }\end{array}$} \\
\hline
\end{tabular}

Table 4. Parametric analysis of comparability for absolute neutrophil counts (pharmacodynamic population).

\begin{tabular}{|c|c|c|c|c|c|c|}
\hline \multirow[t]{2}{*}{ Parameter } & \multicolumn{2}{|c|}{ RGB-02 } & \multicolumn{2}{|c|}{ Neulasta $^{\circledR}$} & \multirow[t]{2}{*}{ Ratio $\ddagger$} & \multirow[t]{2}{*}{$\mathrm{Cl}^{\S}$} \\
\hline & $\mathrm{N}$ & Adjusted mean ${ }^{\dagger}$ & $\mathbf{N}$ & Adjuste & & \\
\hline $\mathrm{ANC}_{\max }\left(\times 10^{9} / \mathrm{I}\right)$ & 129 & 28.585 & 129 & 28.632 & 99.83 & $(96.06,103.75)$ \\
\hline $\begin{array}{l}\text { ANC AOBEC }_{0 \text {-tlast }} \\
\left(\times 10^{9} \cdot \mathrm{h} / \mathrm{l}\right)\end{array}$ & 129 & 3380 & 129 & 3350 & 101.0 & $(97.21,104.94)$ \\
\hline $\begin{array}{l}\text { ANC AUC }_{0 \text {-tlast }} \\
\left(\times 10^{9} \cdot \mathrm{h} / \mathrm{l}\right)\end{array}$ & 129 & 4950 & 129 & 4880 & 101.27 & $(99.01,103.57)$ \\
\hline \multicolumn{7}{|c|}{$\begin{array}{l}\text { Results obtained from parametric analysis of } \log _{\mathrm{e}} \text {-transformed pharmacodynamic parameters in } \\
\text { effects and baseline concentrations fitted as a covariate. } \\
{ }^{\dagger} \text { Adjusted geometric mean from ANCOVA. } \\
{ }^{\ddagger} \text { Ratio of adjusted geometric means defined as RGB-02/Neulasta. } \\
{ }^{\S} \mathrm{CI} \text { for ratio of adjusted geometric means. } \\
\text { ANC: Absolute neutrophil count; ANCOVA: XXX; AOBEC: Area over the baseline effect curve. }\end{array}$} \\
\hline
\end{tabular}

The results from the second comparative PK/PD Study RGB-02-001 demonstrated high level of similarity between RGB-02 and Neulasta based on all PD parameters measured.

\section{Overview of clinical efficacy}

In order to demonstrate clinical efficacy and safety of RGB-02, a prospective, randomized multicenter, double-blind study (study code RGB-02-101) was designed and performed in patients with the aim to show comparability with the originator product Neulasta. The study population, women with breast cancer receiving chemotherapy, was similar to all three efficacy studies conducted in support of the regulatory approval of Neulasta [48,49]. However, in order to have an even more homogeneous population for comparison, in line with the principles of biosimilar development, the study was restricted to patients with stage IIB/III disease, thereby excluding stage IV. Eligible patients were required to have a performance status of less than Eastern Cooperative Oncology Group 2 and had to be chemotherapy naive.

The patients were randomized to receive either RGB-02 treatment or Neulasta. The study objectives were selected to collect sufficient efficacy data for treatment comparison and to collect safety information over a period of time in order to build a safety database of relevant size.

The chosen study design included a therapeutic switch from Neulasta to RGB-02 in order to maximize patient exposure to RGB-02 for the longest period of time, thereby increasing the RGB-02 safety database to the largest possible and also to collect data on the safety of therapy switch from the reference product to RGB-02. Patients received treatment on a 1:1 randomization basis for the first two chemotherapy cycles and those in the Neulasta arm were then transferred to RGB-02 treatment for cycles 3 and 4. After completion of four chemotherapy cycles, there was an option for patients to continue chemotherapy and receive RGB-02 for a further two cycles (cycles 5 and 6) at the discretion of the investigator. Thus, patients in the RGB-02 arm were exposed to the test product for up to six administrations, whereas patients receiving Neulasta were exposed to two administrations and received RGB-02 for up to four administrations afterwards. The primary end point in this study was duration of severe neutropenia (DSN), i.e., the number of days with an ANC $<0.5 \times 10^{9} / 1$ in cycle 1 ; DSN in cycles 2,3 and 4 


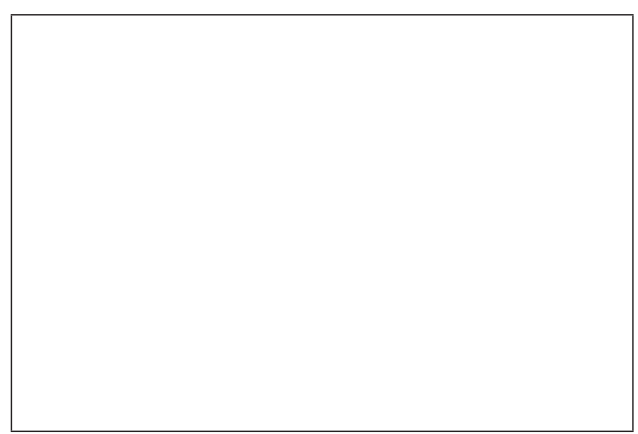

Figure 1. Mean ( \pm standard deviation) absolute neutrophil count values by day and treatment arm: cycle 1 (per protocol population).

ANC: Absolute neutrophil count; PP: Per protocol; SD: Standard deviation.

were assessed as secondary end points. Other secondary end points were related to the incidence of severe- and febrile-neutropenia, time to ANC recovery and depth of ANC nadir, and were used also in the preceding clinical trials supporting the approval of Neulasta.

The chemotherapy regimen identical to the regimen used in the pivotal Neulasta breast cancer studies comprised a combined treatment regimen and dose of docetaxel $75 \mathrm{mg} / \mathrm{m}^{2}$ and doxorubicin $60 \mathrm{mg} / \mathrm{m}^{2}$ [25]. This standard of care regimen constitutes an effective treatment and has been reported to result in an almost $100 \%$ incidence of severe neutropenia with a mean duration of 5-7 days without filgrastim support. Therefore it was considered appropriate for investigating the therapeutic efficacy of pegfilgrastim without compromising the chemotherapy treatment outcome in patients [50,51].

Equivalence margins of -1.00 and +1.00 day duration of neutropenia for demonstration of comparable efficacy between test and reference were applied for the primary end point DSN in cycle 1 . Altogether 240 patients had to be recruited (at least 111 evaluable patients per treatment arm) in order to achieve $90 \%$ power at the $5 \%$ significance level.

The clinical results from Study RGB-02-101 clearly confirmed a comparable efficacy of RGB-02 to Neulasta. The mean ANC values by day and treatment arm during cycle 1 for the cycle population are displayed in Figure 1 . It can be depicted from this figure that the ANC characteristics in cycle 1 are very similar for both compounds; they have practically the same effect on the ANC count each day indicating similar efficacy of RGB-02 and Neulasta.

Clinical similarity of the two products is fully supported by the primary end point results. The mean and least squares (LS) mean DSN values in cycle 1 for test and reference were similar, with an LS mean for difference of 0.1 day (Table 5). The lower and upper limits of the CIs for the difference were well within the predefined acceptance ranges of \pm 1 day. Therefore, it can be concluded that RGB- 02 and Neulasta have an equivalent treatment effect.

The same results could be obtained in cycle 2 where an equivalent sustained treatment effect of RGB-02 and Neulasta (Table 5) could be shown: the mean and the LS mean DSN values for RGB-02 and Neulasta were similar and there was no statistically significant difference between the treatments.

The results for cycles 3 and 4, in which all patients received RGB-02, continue to demonstrate the persistence of efficacy of RGB-02. The results were analyzed according to the initial treatment allocation and the mean DSN values were $<1$ day in both cycles and treatment arms, indicating that efficacy of RGB-02 persists and that the switch from Neulasta to RGB-02 is safe and preserves efficacy.

All other secondary end points showed also very similar results for both treatment groups.

The incidence of severe neutropenia in cycles 1 and 2 was comparable since most of the patients in the first cycle and approximately half of the patients in the second cycle developed severe neutropenia as expected for the chemotherapy combination selected for this study.

The observed incidence for febrile neutropenia was low in cycle 1 and similar for RGB-02 and Neulasta, and no cases of febrile neutropenia were reported in cycle 2. Likewise, a low overall incidence of febrile neutropenia was observed for both treatment groups and there was no statistically significant difference between the treatments.

The results for time to ANC recovery in cycles 1 and 2 showed that all patients fully recover the neutrophil count after chemotherapy treatment. Mean values for RGB-02 and Neulasta were similar for each cycle and the median 


\begin{tabular}{|c|c|c|c|}
\hline & RGB-02 & Neulasta ${ }^{\circledR}$ & Difference (RGB-02 - Neulasta) \\
\hline \multicolumn{4}{|l|}{ Cycle 1, PP population } \\
\hline Mean (SD) & $1.7(1.14)$ & $1.6(1.31)$ & \\
\hline Least squares mean $(95 \% \mathrm{Cl})$ & $1.5(1.2,1.8)$ & $1.4(1.1,1.7)$ & $0.1(-0.2,0.4)$ \\
\hline \multicolumn{4}{|l|}{ Cycle 1, FAS } \\
\hline Mean (SD) & $1.8(1.28)$ & $1.7(1.45)$ & \\
\hline Least squares mean $(95 \% \mathrm{Cl})$ & $1.6(1.3,1.9)$ & $1.4(1.1,1.7)$ & $0.1(-0.2,0.4)$ \\
\hline \multicolumn{4}{|l|}{ Cycle 2, PP population } \\
\hline $\mathrm{n}$ & 111 & 100 & \\
\hline Mean (SD) & $0.7(0.81)$ & $0.7(0.97)$ & \\
\hline Mean (SD) & $0.7(0.81)$ & $0.9(1.31)$ & \\
\hline Least squares mean $(95 \% \mathrm{Cl})$ & $0.5(0.3,0.8)$ & $0.8(0.5,1.0)$ & $-0.2(-0.5,0.1)$ \\
\hline
\end{tabular}

time to recovery was 3 days in both arms and in both cycles. The depth of ANC nadir calculated as the change from baseline to the lowest values was also similar for both cycles 1 and 2 .

In conclusion, analysis of the primary efficacy end point, DSN in cycle 1 has demonstrated treatment equivalence between RGB-02 and Neulasta. This is supported by the analysis of all secondary efficacy end points, which revealed no meaningful differences between the treatment arms.

\section{Overview of safety}

The safety profile of RGB-02 is based on cumulated data obtained from 240 healthy subjects receiving a single dose of RGB-02 in two studies (74080 and RGB-02-001) and from 234 breast cancer patients who received at least one dose of RGB-02 in this study (Study RGB-02-101).

RGB-02 was well tolerated by all involved subjects and the overall incidence and the adverse event profile for RGB-02 was similar to that observed in the patients/healthy volunteers who received Neulasta as comparator in the clinical development program and were consistent with the known safety profile of Neulasta [15]. There was no evidence of any differences in the immunogenic potential of RGB-02 and Neulasta, and no difference was found in safety laboratory parameters.

\section{Conclusion}

Based on the outcome of preclinical investigations and three randomized, double-blind clinical studies, treatment equivalence between RGB-02 and Neulasta was demonstrated. Treatment switch from the original agent to the biosimilar did not raise either efficacy or safety concerns. 
Acknowledgements

The contribution of the co-investigators of Study RGB-02-101 [48,49] is highly acknowledged.

Conflict of interest

The studies were funded by Gedeon Richter Plc. During the conduct of Study RGB-02-101, Z Kahán had a consultancy agreement with Gedeon Richter Plc. A Illes, I Aradi and K Horvat-Karajz are employees of Gedeon Richter Plc. D Sántha has no conflict of interest. The authors have no other relevant affiliations or financial involvement with any organization or entity with a financial interest in or financial conflict with the subject matter or materials discussed in the manuscript apart from those disclosed.

\section{References}

Papers of special note have been highlighted as: $\bullet$ of interest

1 Bray F, Ferlay J, Soerjomataram I et al. Global cancer statistics 2018: GLOBOCAN estimates of incidence and mortality worldwide for 36 cancers in 185 countries. CA Cancer J. Clin. doi:10.3322/caac.21492 (2018) (Epub ahead of print).

2 Siegel RL, Miller KD, Jemal A. Cancer statistics, 2018. CA Cancer J. Clin. 68(1), 7-30 (2018).

3 Roser M, Ritchie H. Cancer. (2018). www.ourworldindata.org/cancer

4 Jönsson B, Hofmarcher T, Lindgren P, Wilking N. The cost and burden of cancer in the European Union 1995-2014. Eur. J. Cancer 66, 162-170 (2016).

5 Menyhárt O, Fekete JT, Gy̋̋rffy B. Demographic shift disproportionately increases cancer burden in an aging nation: current and expected incidence and mortality in Hungary up to 2030. Clin. Epidemiol. 10, 1093-1108 (2018).

6 Smith TL, Bohlke K, Lyman GH et al. Recommendations for the use of WBC growth factors: American Society of Clinical Oncology clinical practice guideline update. J. Clin. Oncol. 33(28), 3199-3212 (2015).

7 Aapro MS, Cameron DA, Pettengell R et al. EORTC guidelines for the use of granulocyte-colony stimulating factor to reduce the incidence of chemotherapy-induced febrile neutropenia in adult patients with lymphomas and solid tumours. Eur. J. Cancer 42(15), 2433-2453 (2006).

8 Aapro MS, Bohlius J, Cameron DA et al. 2010 update of EORTC guidelines for the use of granulocyte-colony stimulating factor to reduce the incidence of chemotherapy-induced febrile neutropenia in adult patients with lymphoproliferative disorders and solid tumours. Eur. J. Cancer 47(1), 8-32 (2011).

9 National Comprehensive Cancer Network. www.nccn.org/professionals/physician_gls/pdf/myeloid_growth.pdf

10 Crawford J, Caserta C, Roila F et al. Hematopoietic growth factors: ESMO clinical practice guidelines for the applications. Ann. Oncol. (Suppl 5), v248-51 (2010).

11 Klastersky J, de Naurois J, Rolston K et al. Management of febrile neutropenia: ESMO clinical practice guideline. Ann. Oncol. 27(suppl 5), v111-118 (2016).

12 Panopoulos AD, Watovich SS. Granulocyte colony-stimulating factor: molecular mechanism of action during steady state and 'emergency' hematopoiesis. Cytokine 42(3), 277-288 (2008).

13 US FDA. www.accessdata.fda.gov/scripts/cder/daf/index.cf m?event=overview.process\&applno=103353

14 Yang BB, Kido A. Pharmacokinetics and pharmacodinamics of pegfilgastrim. Clin. Pharmacokinet. 50(5), 295-306 (2011).

15 Neulasta $\AA$, prescribing information. Amgen, Inc., CA, USA (2015). www.accessdata.fda.gov/drugsatfda_docs/label/2015/125031s170s179s181lbl.pdf

16 US FDA. www.accessdata.fda.gov/scripts/cder/daf/index.cf m?event=overview.process\&applno=125031

17 EMA. Lonquex ${ }^{\circledR}$ : summary of product characteristics. www.ema.europa.eu/documents/product-information/lonquex-epar-product-information_en.pdf

18 Hoggatt J, Tate TA, Pelus LM. Role of lipegfilgrastim in the management of chemotherapy-induced neutropenia. Int. J. Nanomed. 10, 2647-2652 (2015).

19 Wolff T, Schulz H, Losem C et al. Prophylaxis of chemotherapy-induced neutropenia and febrile neutropenia with lipegfilgrastim in patients with non-Hodgkin lymphoma (NADIR study). Eur. J. Haematol. doi:10.1111/ejh.13189 (2018) (Epub ahead of print).

20 Danova M, Chiroli S, Rosti G, Doan QV. Cost-effectiveness of pegfilgrastim versus six days of filgrastim for preventing febrile neutropenia in breast cancer patients. Tumori 95, 219-226 (2009).

21 Lyman GH, Lalla A, Barron RL, Dubois RW. Cost-effectiveness of pegfilgrastim versus filgrastim primary prophylaxis in women with early-stage breast cancer receiving chemotherapy in the United States. Clin. Ther. 31, 1092-1104 (2009).

22 Neupogen $\AA$, prescribing information. Amgen, Inc., CA, USA (2013). www.accessdata.fda.gov/drugsatfda_docs/label/2013/103353s5157lbl.pdf 
23 Bondarenko I, Gladkov OA, Elsaesser R et al. Efficacy and safety of lipegfilgrastim versus pegfilgrastim: a randomized, multicenter, active-control Phase III trial in patients with breast cancer receiving doxorubicin/docetaxel chemotherapy. BMC Cancer 13(1), 386 (2013).

24 Green MD, Koelbl H, Baselga J et al. A randomized double-blind multicenter Phase III study of fixed-dose single-administration pegfilgrastim versus daily filgrastim in patients receiving myelosuppressive chemotherapy. Ann. Oncol. 14(1), 29-35 (2003).

25 Holmes FA, O'Shaughnessy JA, Vukelja S et al. Blinded, randomized, multicenter study to evaluate single administration pegfilgrastim once per cycle versus daily filgrastim as an adjunct to chemotherapy in patients with high-risk stage II or stage III/IV breast cancer. J. Clin. Oncol. 20(3), 727-731 (2002).

26 Almenar D, Mayans J, Juan O et al. Pegfilgrastim and daily granulocyte colony-stimulating factor: patterns of use and neutropenia-related outcomes in cancer patients in Spain-results of the LEARN Study. Eur. J. Cancer Care 18(3), 280-286 (2009).

27 Pfeil AM, Alcott K, Pettengell R et al. Efficacy, effectiveness and safety of long-acting granulocyte colony-stimulating factors for prophylaxis of chemotherapy-induced neutropenia in patients with cancer: a systematic review. Support. Care Cancer 23(2), 525-545 (2015).

- A comprehensive literature review of long-acting granulocyte colony-stimulating factors.

28 Klastersky J, Awada A. Prevention of febrile neutropenia in chemotherapy-treated cancer patients: pegylated versus standard myeloid colony stimulating factors. Do we have a choice? Crit. Rev. Oncol. Hematol. 78(1), 17-23 (2011).

29 Cerchione C, De Renzo A, Di Perna M et al. Pegfilgrastim in primary prophylaxis of febrile neutropenia following frontline bendamustine plus rituximab treatment in patients with indolent non-Hodgkin lymphoma: a single center, real-life experience. Support. Care Cancer 25(3), 839-845 (2017).

30 Cerchione C, De Renzo A, Nappi D et al. Pegfilgrastim in primary prophylaxis of febrile neutropenia in elderly patients with hematological malignancies-bendamustine and G-CSF support. Support. Care Cancer doi: 10.1007/s00520-019-4651-5 (2019) (Epub ahead of print).

31 Luengo-Fernandez R, Leal J, Gray A, Sullivan R. Economic burden of cancer across the European Union: a population-based cost analysis. Lancet Oncol. 14(12), 1165-1174 (2013).

32 Inotai A, Csanadi M, Vitezic D et al. Policy practices to maximise social benefit from biosimilars. J. Bioequivalence Bioavailability 9(4), $467-472$ (2017).

33 Inotai $\mathrm{A}$, Prins CPJ, Csanádi $\mathrm{M}$ et al. Is there a reason for concern or is it just hype? - systematic literature review of the clinical consequences of switching from originator biologics to biosimilars. Expert Opin. Biol. Ther. (8), 915-926 (2017).

- Comprehensive evaluation of the barriers of switching from originator biologics to biosimilars based on various types of studies.

34 Tabernero J, Vyas M, Giuliani R et al. Biosimilars: a position paper of the European Society for Medical Oncology, with particular reference to oncology prescribers. ESMO Open 1, e000142 (2016).

- The most recent guideline and comprehensive overview on the best utilization of biosimilars.

35 Curigliano G, O’Connor PD, Rosenberg JA, Jacobs I. Biosimilars: extrapolation for oncology. Clin. Rev. Oncol. 104, 131-137 (2016).

36 Declerck P, Danesi R, Petersel D, Jacobs I. The language of biosimilars: clarification, definitions, and regulatory aspects. Drugs 77 , 671-677 (2017).

37 Deloitte. Winning with biosimilars opportunities in global market. www2.deloitte.com

38 Wolff-Holz E, Garcia Burgos J, Giuliani R et al. Preparing for the incoming wave of biosimilars in oncology. ESMO Open 3, e000420 (2018).

39 Inotai A, Csanadi M, Petrova G et al. Patient access, unmet medical need, expected benefits, and concerns related to the utilisation of biosimilars in Eastern European countries: a survey of experts. Biomed Res. Int. doi:10.1155/2018/9597362 (2018) (Epub ahead of print).

- Comprehensive analysis of the clinical and payer aspects of biosimilar use with special regard to lower income economies.

40 European Medicines Agency. Annex to guideline on similar biological medicinal products containing biotechnology-derived proteins as active substance: non-clinical and clinical issues. Guidance on similar medicinal products containing recombinant granulocyte-colony stimulating factor. EMEA/CHMP/BMWP/31329/2005 (2006). www.ema.europa.eu

41 European Medicines Agency. Guideline on clinical trials with haematopoietic growth factors for the prophylaxis of infection following myelosuppressive or myeloablative therapy. EMEA/CPMP/555/95 (2007). www.ema.europa.eu

42 European Medicines Agency. Guideline on immunogenicity assessment of biotechnology-derived therapeutic proteins. EMEA/CHMP/BMWP/14327/2006 (2017). www.ema.europa.eu

43 Zielinska J, Bialik W. Recent changes on the biopharmaceutical market after the introduction of biosimilar G-CSF products. Oncol. Clin. Pract. 12(4), 144-152 (2016).

44 European Medicines Agency. Medicines. (2018). www.ema.europa.eu/medicines/field_ema_web_categories\%253Aname_field/Human/e ma_group_types/ema_medicine/field_ema_med_status/authorised-36/ema_medicine_types/field_ema_med_biosimilar/search_api_aggrega tion_ema_medicine_types/field_ema_med_biosimilar 
45 US FDA. Biosimilar product information. (2018). www.fda.gov/drugs/developmentapprovalprocess/howdrugsaredevelopedandapprov ed/approvalapplications/therapeuticbiologicapplications/biosimilars/ucm580432.htm

46 European Medicines Agency. Guideline for good clinical practice E6 (R2). EMA/CHMP/ICH/135/1995. www.ema.europa.eu

47 EMA. CHMP assessment report for Zarzio. https://www.ema.europa.eu/documents/assessment-report/zarzio-epar-public-assessment-report_en.pdf

48 Horvat-Karajz K, Grecea D, Smakal M, Illes A, Kahan Zs. Efficacy and safety of RGB-02, a proposed biosimilar pegfilgrastim to prevent chemotherapy-induced neutropenia: results of a randomized, double-blind, Phase III clinical study vs. reference pegfilgrastim in patients with breast cancer receiving docetaxel/doxorubicin. Ann. Oncol.doi:10.1093/annonc/mdx388.033 (2017) (Epub ahead of print).

49 Illes A, Perjesi L, Horvat-Karajz K et al. Safe switch of treatment from the reference product to RGB-02, a proposed biosimilar pegfilgrastim: analysis of the results of three clinical trials. Ann. Oncol.doi:10.1093/annonc/mdy300.017 (2018) (Epub ahead of print).

50 Nabholtz JM, Riva A. Taxane/anthracycline combinations: setting a new standard in breast. Cancer Oncologist 6(Suppl 3), 5-12 (2001).

51 Nabholtz JM, Falkson C, Campos D et al. Docetaxel and doxorubicin compared with doxorubicin and cyclophosphamide as first-line chemotherapy for metastatic breast cancer: results of a randomized, multicenter, Phase III trial. J. Clin. Oncol. 21(6), 968-975 (2003). 